Article

\title{
Critical factors influencing online consumer preference towards cash on delivery method in Sri Lanka
}

\author{
Navodika Karunarathna ${ }^{1 *}$ \\ ${ }^{1}$ Department of Information Management; SLIIT (Sri Lanka Institute of Information Technology) Business \\ School, Malabe, Sri Lanka; navo20piumikarunarathna@gmail.com \\ * Correspondence: navo20piumikarunarathna@gmail.com
}

Received: 18October 2020; Accepted: 13 January 2021; Published: 5 February 2021

\begin{abstract}
With the rapid technological advancements, E-commerce deliveries in Sri Lanka have been flourishing tremendously. However, payments have still been identified as one of the main obstacles to the developments of the E-commerce sector. The Cash on Delivery (COD) method has played a significant role in driving the growth of the E-commerce industry and accounts for more than $60 \%$ of all E-commerce transactions in Sri Lanka. Although COD is so important, many companies still waver with its processes as it has become a notoriously problematic area in terms of on-time and successful deliveries. Hence, the purpose of this study was to investigate the critical factors influencing online customers' preference of cash on the delivery method to provide insights into the management of Ecommerce and logistics industries on the usage of appropriate payment methods for E-commerce transactions. This empirical study is based on the primary data obtained through a survey conducted among Sri Lankan online customers. The data were analyzed using the Partial Least SquaresStructural Equation Modelling technique. Consequently, 'Sri Lankan origin of the online seller,' 'Selling specialized products by the online seller,' 'Availability of wide choice of payment methods,' 'Offering a wide assortment of foreign products by the online seller,' 'Lack of trust on online payments' has been identified as the critical factors influencing Sri Lankan online customers' preference of cash on delivery method.
\end{abstract}

Keywords: E-commerce, Cash on Delivery, Online Shopping, E-retailers

JEL codes: $L 81$

\section{Introduction}

With the rapid technological advancements, E-commerce deliveries in Sri Lanka have been flourishing tremendously. Most Sri Lankan E-retailers and logistics service providers have developed new platforms to step into the contemporary E-commerce trends to meet the dynamic demands. Ecommerce delivery services have offered considerable coverage in Sri Lanka through the connection of local and international marketplaces to everyone's doorstep. Sri Lankan E-commerce delivery services are currently involved in providing a wide range of products and services such as household items, apparel, medicines, numerous raw materials, construction items, small or large machinery, travel facilities, education, and many more very fast with reasonable prices to the consumers. Sri Lankan E-commerce delivery services allow customers to order anything they need remaining their residences. Highly affordable when compared to physical delivery services, offering various discounts, providing high-quality services and goods, and offering multiple fast and excellent solutions for the delivery can be identified as the reasons for seeking E-commerce services by Sri Lankan Customers. 
The Cash on Delivery (COD) service has played a significant role in driving the growth of Ecommerce in the world. Cash on Delivery is a term used to describe the goods paid upon delivery. This is opposed to the usual prepayment procedure where goods are purchased and then delivered subsequently. Instantly receiving goods, instead of waiting days or weeks for arrival, allowing the sender to receive instant payment instead of waiting for the credit payment, providing a chance for the customer to review and audit the product before making payment to the delivery driver, thereby reducing returns and future customer friction can be identified as the key advantages of COD method. All the significant logistics and courier companies worldwide serving direct end-customers through E-commerce deliveries consider cash on delivery management as a critical transaction method that has sustained its popularity, notwithstanding multiple payment options gaining ground. However, if COD is so essential, many companies still waver with its processes as the COD service has become a notoriously problematic area for on-time and successful deliveries. As a result of the prior literature review study of the author, it was revealed that an empirical research that is specially designed on the COD method has not yet been conducted in the Sri Lankan context. Therefore, the purpose of this empirical study was to investigate the critical factors influencing Sri Lankan online customers' preference of cash on the delivery method to provide insights into the management of E-commerce and logistics industries on the usage of appropriate payment methods for E-commerce transactions.

The paper is structured as follows. Section 2 provides a literature review on the COD method and its role in Sri Lankan and the global E-commerce sector, whereas Section 3 focuses on the research methodology used in the study as well as the research hypotheses and conceptual research model. The results of empirical research conducted based on partial least squares structural equation modeling are presented in section 4 and section 5 provides discussion and managerial implications through the results obtained. Section 6 contains the conclusion comprising the limitations and future research directions.

\section{Literature Review}

\subsection{Cash on Delivery Method}

The Cash on Delivery (COD) service has been playing a significant role in powering the growth of E-commerce worldwide. "Cash on delivery is the process of shoppers paying for a product in person on its delivery. If the COD buyer fails to make the payment, the product is returned to the seller" (Dudharejia, 2018). "The recipient can make payment by cash, certified check or money order, depending on what is the shipping contract stipulates" (JetEx, 2018). All the major logistics and courier companies over the world serving direct end-customers through E-commerce deliveries consider cash on delivery management as a key transaction method that has sustained its popularity, notwithstanding multiple payment options gaining ground. "This is sometimes called "post-payment" system because the customer receives goods before making a payment" (Pencarelli, et al., 2018). It has been statistically proved that E-commerce stores that offer COD services attract more online buyers than the ones who are limited to online payment gateways (courier.lk, 2020). This website has stated five main reasons why E-commerce businesses should practice COD services such as Buyers prefer COD to online payment methods, Assurance of receiving money, Promotes impulse purchases, No space for fraudulent refunds, and Building trust (courier.lk, 2020). More comfortable with cash payments than digital, Lack of digital payment infrastructures, Lack of trust in online payments, and Absence of cyber laws were identified as the reasons for selecting the COD in developing economies (Dudharejia, 2018).

COD as a payment method provides enormous advantages for both consumers and retailers similarly. According to Ambekar (2011), Being able to place orders online even without possessing a credit/debit card, Being able to pay when the item has arrived, Reduced chances of online frauds can be identified as the benefits of COD gained by the customers whereas the benefits gained by retailers are Reaching a wider base of customers such as students, housewives who typically do not have a credit/debit card, Offering the service as a differentiator concerning competition, Simplified business 
processes; if the customer chooses not to accept delivery, there is no refund as there has been no payment. Similarly, Bhalla (2019) also stated the advantages of COD such as Flexible payment options for the customer, the ability to check the product and see whether everything is perfect before paying for it, No dependency on payment cards, and No online payment frauds. Besides enjoying the advantages of COD transactions, retailers providing this payment option need to be prepared to take on some risks. Since when the goods arrive, the consumer may refuse delivery, the seller may wind up carrying the shipping costs for the returned items (JetEx, 2018). Filling of the invoices with the shippers, Transferring the cash, Handling all the cash daily via the busy schedules of delivery associates can be identified as some issues involved in COD transactions (LogiNext, 2017). Bhalla (2019) also stated the disadvantages of the COD method such as Seller vulnerable to losses when the customer returns the product without paying for it and Courier companies charge the customer an amount when customer opt for the cash on delivery payment option. Puneet Bhalla (2019) has described the COD process in the context of E-commerce, and typically, these E-commerce companies ship via their logistics or hire a separate logistics partner for delivering consignments and collecting payment. Aggregating this information, the following diagram (Figure 1) was created to illustrate the COD process in the context of E-commerce.

Figure 1. Process of Cash on Delivery in E-commerce

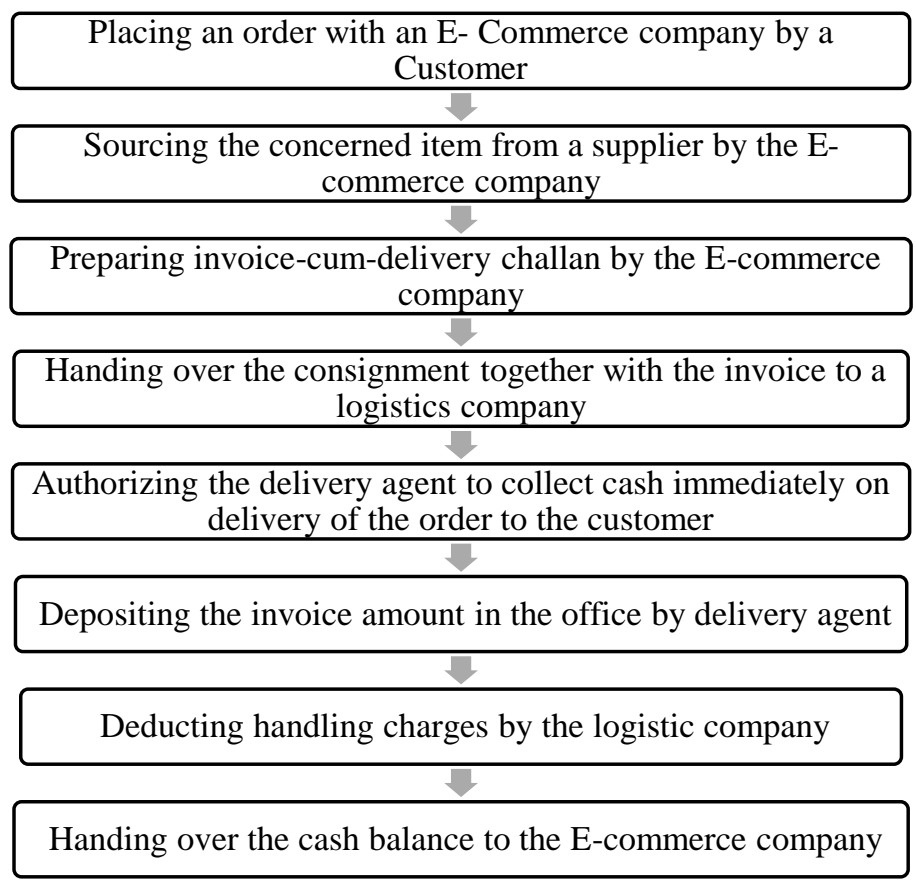

\subsection{Cash on Delivery Services in Sri Lankan Context}

To identify the current status of Cash on Delivery Services in the Sri Lankan Context, the content of relevant websites was reviewed.

Payments have always been one of the main obstacles to online shopping in Sri Lanka. Sri Lanka has made some strides in creating a safer atmosphere for online transactions and acceptance of payments, yet where it should be is still not close (Howson, 2017). Therefore, most developing economies like Sri Lanka tend to have customers with a strong cash preference. Cash on delivery transactions in Sri Lanka is improving E-commerce. This option is also popular with many younger consumers who don't have a credit card yet and low credit consumers who don't have any other means to pay for online products (JetEx, 2018). According to the survey that was conducted by a Colombobased think tank from December 2018 to January 2019 in Sri Lanka, it has been revealed that most Ecommerce users preferred transactions with cash and debit cards while only $2 \%$ of them preferred to use Internet banking or mobile money (Fernando, 2019). "More than $60 \%$ of all eCommerce in Sri Lanka 
is paid for using COD" (DeliveryMalli, 2017). Based on a survey conducted by Dias \& Ranwala (2015) on determinants of consumer satisfaction on e-procurement/ online purchasing in Sri Lanka, it has been identified that most consumers are dissatisfied with response time, security, privacy, transaction ability, delivery speeds, and customer service after-sales. Further, this study has suggested recommendations to enhance online purchasing in Sri Lanka such as the development of local online websites, secure delivery of packages, video facility for product description, and introducing "payment cash" method. Cash on Delivery can therefore be defined as a feasible marketing choice available with online shops leading increasingly to their high popularity among people. "While participants of global online marketing highly enjoy Cash on Delivery options, the number engages in Cash on Delivery marketing in Sri Lanka is also getting high in recent times" (courier.lk, 2020). Further, this site indicates that most online shops or new companies that are not capable of maintaining their own COD services, hire third-party courier services in this regard to provide reliable COD services to their customers and to obtain other value-added services like return options (courier.lk, 2020). When it is reviewed by the websites of logistics and courier service providers, it can be identified that they have been competitively engaging in providing a wide range of COD services to their customers- E-retailers.

\subsection{Cash on Delivery Services in the Global Context}

Currently, 70 to $80 \%$ of E-commerce transactions are paid through the COD method, with the highest online payment in the United Arab Emirates (UAE) and the lowest in Saudi Arabia and Egypt (Fallouh, 2019). Most developing economies tend to have customers with a strong cash preference. "Amazon international website also adopted the COD payment to UAE during 2016 acknowledging the popularity and necessity of the payment method in this region" (Fallouh, 2019). "In particular, in sub-Saharan Africa, only 34\% of residents over the age of 15 have a bank account, and $50 \%$ of ecommerce transactions are paid by cash on delivery" (WorldEconomicForum, 2018). COD has become a prevalent mode of payment for online shopping in some countries like India, Bangladesh, and Thailand, and so on (Bhalla, 2019). More than 50 \% of E-commerce transactions in India, dependent on the cash-on-delivery mode of payment, and this system has been designed to attract mainly rural consumers who didn't have access to digital payment systems (Dudharejia, 2018). As stated in ETNowDigital (2019), Cash on delivery accounts for $65 \%$ of all orders from Indian online marketplaces but One-third of cash on delivery orders from E-commerce websites is not delivered. It further noted that COD orders are returned due to several issues. "A non-delivery process starts with the carrier being unable to deliver the customer's order due to his or her unavailability" (ETNowDigital, 2019). Considering the evolving E-commerce sector in India, Kumar (2015) has discussed the role of logistics in E-commerce deliveries by emphasizing the importance of professional logistics services provided by the courier and third-party logistics providers to improve customer retention. This study stated that online stores had to come up with lenient return policies and cash-on-delivery options to increase customer satisfaction in India.

According to the study of Arora, Srivastava, \& Majumder(2017), (Arora, et al., 2017) it is stated that around $80 \%$ of customers select COD and it has led to slower delivery service as each transaction takes extra time to complete. "In the context of demonetization E-commerce giants like Amazon and Flipkart took no time to stop their cash on delivery options and educated their customers about the benefits of e-cash payments" (Jana, 2017). Pencarelli, Skerhakova, Taha, \& Valentiny (2018) conducted a study to determine the factors affecting Italian online shoppers in their primary payment method preferences whenever the COD payment option is available. This research has revealed that perceived security, privacy, and trust have a significant influence on the customers' intention to adopt a COD payment method. Further, this study found few important facts regarding the COD payment method such as an increase of the frequency of online shopping leads to a slight increase in using cash-ondelivery as a payment method, the more important the factor of the online seller's reputation is, the lower the likelihood of preference for a COD payment method and local origin of the online seller increases the preference COD payment method (Pencarelli, et al., 2018). Polasik \& Fiszeder (2010) analyzed factors influencing the acceptance of the seven major payment methods by the polish 
managers of online shops and the results of this study demonstrated that a shop's strategy of using traditional and electronic distribution channels, preferences of online shop managers, the involvement in online auctions and cross-border sales have significant influences on its acceptance of particular payment methods.

\section{Methodology}

\subsection{Empirical Hypothesis}

The main objective of the study was to investigate the critical factors that impact E-commerce customers' preference of cash on delivery method in Sri Lanka. As a result of the literature review, the potential research hypotheses for this study were initially identified from a study done by Pencarelli, Skerhakova, Taha, \& Valentiny (2018). Additionally, a few new hypotheses were also developed reviewing the content of E-commerce websites. Subsequently, the following research hypothesis was developed to achieve the objective of this study.

H1 - The frequency of online shopping (Frequency) has a statistically significant effect on the preference of the COD payment method while shopping online.

H2 - Monthly budget dedicated exclusively for online shopping (E-budget) has a statistically significant effect on the preference of the COD payment method while shopping online.

H3 - The maximum amount of one transaction in online shopping [Max_per-one] has a statistically significant effect on the preference of the COD payment method while shopping online.

H4 - The Sri Lankan origin of the online seller [SL_shop] has a statistically significant effect on the preference of the COD payment method while shopping online.

H5 - Being an online seller who pays taxes in Sri Lanka [SL_tax] has a statistically significant effect on the preference of the COD payment method while shopping online.

H6 - Locating the call center in the online seller's home country [Home_land_cc] has a statistically significant effect on the preference of the COD payment method while shopping online.

H7 - Offering a wide assortment of domestic products by the online seller [ $\mathbf{W}$-assortment_dp] has a statistically significant effect on the preference of the COD payment method while shopping online.

H8 - Offering a wide assortment of foreign products by the online seller [W-assortment_fp] has a statistically significant effect on the preference of the COD payment method while shopping online.

H9 - Selling specialized products by the online seller [Spec_prod] has a statistically significant effect on the preference of the COD payment method while shopping online.

H10 - Lower prices of online seller's products compared to competitors [Low_price] have a statistically significant effect on the preference of the COD payment method while shopping online.

H11 - Overall design of the e-shop [Design_e-s] has a statistically significant effect on the preference of the COD payment method while shopping online.

H12 - Special offers of e-shop (special packaging, free delivery, etc.) [Spec_offer] have a statistically significant effect on the preference of the COD payment method while shopping online.

H13 - The previous reputation of the e-shop [Rep_e-s] has a statistically significant effect on the preference of the COD payment method while shopping online.

H14 - Availability of a wide choice of payment methods [W_pay-m] has a statistically significant effect on the preference of the COD payment method while shopping online.

H15 - The online support of e-shop [E-support] has a statistically significant effect on the preference of the COD payment method while shopping online.

H16 - The free return of product [F-r_prod] has a statistically significant effect on the preference of a particular payment method (COD) while shopping online.

H17 - The online seller's products involvement in activities within the framework of corporate social responsibility [CSR] has a statistically significant effect on the preference of the COD payment method while shopping online.

H18 - The Lack of trust in online payments [L_Trust_epay] has a significant effect on the preference of the COD payment method while shopping online. 
H19- The lack of digital infrastructures [L_Digital_In] has a significant effect on the preference of the COD payment method while shopping online.

H20 - Being able to pay when the item has arrived [Pay_arrival] has a significant effect on the preference of the COD payment method while shopping online.

\subsection{Conceptual Framework}

To analyze the critical factors influencing Sri Lankan online customers' preference of cash on delivery method, a conceptual research model has been formulated and presented in Figure 2. In this research, the acceptance of the COD method as the most preferred payment method has been considered as the dependent variable (dichotomy) and the above hypothetical factors which influence online customers' preference of the COD method were considered as the independent variables. Within the proposed model, these hypothetical factors were divided into five major categories: (i) Customer characteristics, (ii) E-shop characteristics, (iii) Benefits of the COD method, and (iv) Drawbacks of Online payment options.

Figure 2. Conceptual Research Model

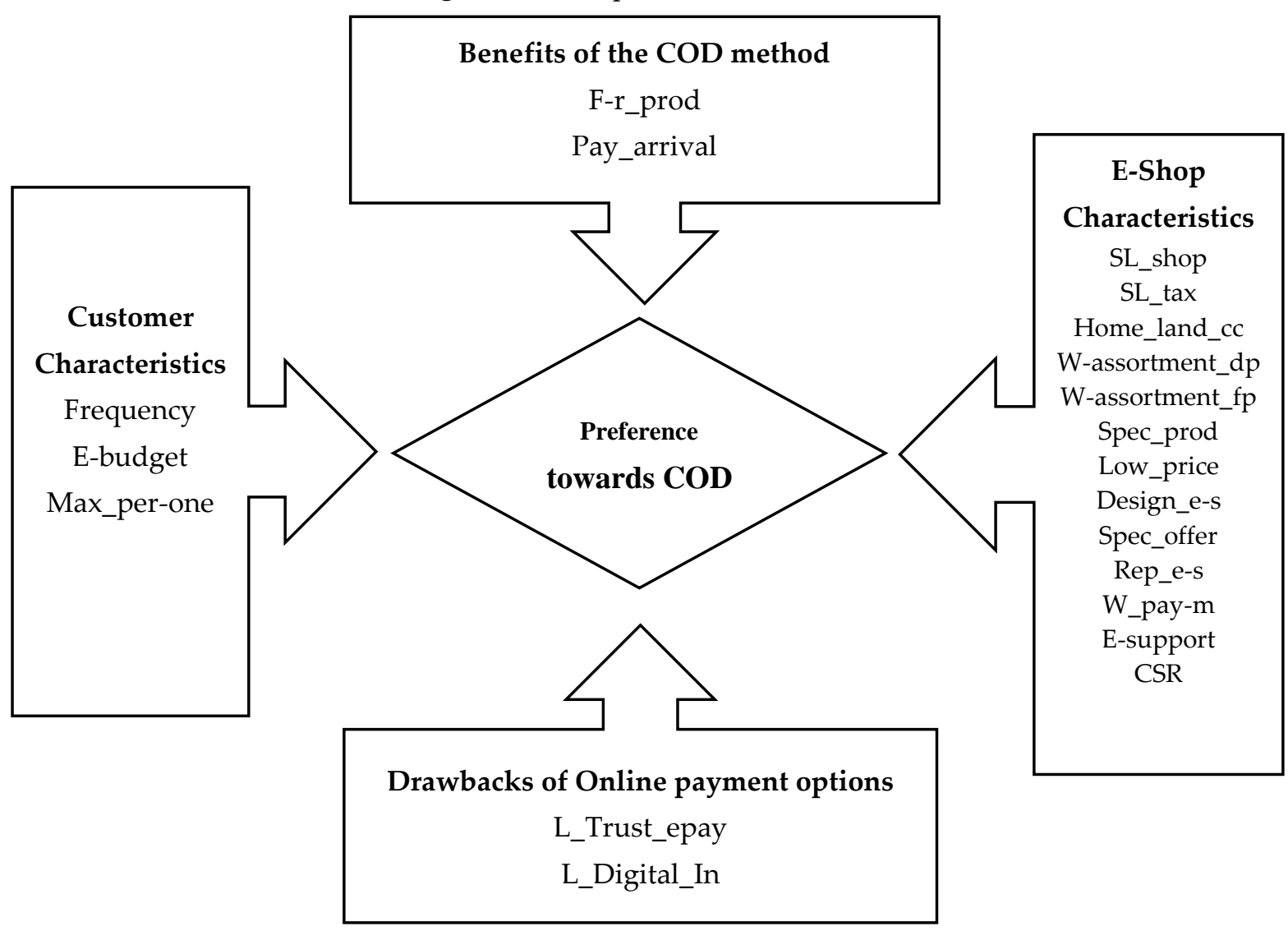

\subsection{Data Collection and Analytical Tools}

The methodology followed by Pencarelli, Skerhakova, Taha, \& Valentiny (2018) and Kumar, Singh, \& Modgil (2020) was mainly referred to to develop the methodology for this study. The data collection was conducted through a self-administered questionnaire which was distributed electronically. Sri Lankan online customers were identified as the target respondents of this study and a customer who prefers to use the COD payment method while shopping online was identified as the unit of analysis. The non-probability sampling technique was used for respondent selection since it was impossible to identify and contact all members of the population. The exponential nondiscriminative snowball sampling method is used as the non-probability sampling technique, as the 
first subject is recruited and then he/she provides multiple referrals. Each new referral then provides more data for referral and so on, until there is enough number of subjects for the sample. Therefore, the sample size had been derived by computing the minimum sample size required for accuracy in estimating proportions by considering the standard normal deviation (z) set at $90 \%$ confidence level(1.645), percentage picking a choice or response $(p-50 \%=0.5)$ and the confidence interval (c-0.05 $= \pm 5)$. The formula used is: $\mathrm{n}=\mathrm{z} 2(\mathrm{p})(1-\mathrm{p}) / \mathrm{c} 2$. Accordingly, the minimum sample size for this study was approximately identified as 270 . The total number of questionnaires was 275 and the total number of response rate was $68.7 \%$. The questionnaire contained 29 items/questions. The first 03 questions of the questionnaire were prepared to get the demographic data of the respondents and the 4th questions were prepared to confirm whether the respondent is a user of COD services or not. If the answer is "no", they were supposed to mention their reasons and to select the preferred payment method in online shopping before leaving the questionnaire. In the question concerning online shopping frequency (H1), there were 5 response options: almost daily, about once a week, about once every two weeks, a month, less than once a month. As regards a question of the monthly budget dedicated exclusively for online shopping (H2), the options were scaled as follows: $<10000$ LKR, $<20000$ LKR, $<50000$ LKR, $<100000$ LKR, and $>100000$ LKR. Afterward, respondents were allowed to state the degree of agreement with the statement on a 5-point scale. Each factor, the importance of which the respondents have determined, is represented by one of the hypotheses $\mathrm{H} 1-\mathrm{H} 20$. Finally, they were supposed to answer the question "Do you feel more comfortable with cash on delivery payment option than digital online shopping payment options?" to get their overview on the COD payment method.

Before using the questionnaire to collect data, it has been pilot tested to refine the questionnaire so that respondents will have no problems in answering the questions and obtaining some assessment of the questions' validity and the likely reliability of the data that will be collected. Initially, an expert in the field of E-commerce deliveries was asked to comment on the appropriateness of the questions and allowed to make suggestions on the structure of the questionnaire. It helped to establish the content validity and enabled to make necessary amendments before pilot testing such as shortening the questions to avoid the unambiguity and to allow respondents to understand the questions straightforwardly. The pilot test was conducted circulating this questionnaire among the group of 10 graduates specialized in the management and IT field with professional experience. As a result of that, the face validity of the questionnaire was established by getting ideas on whether the questionnaire appears to make sense. Considering a large number of hypotheses and a small sample size, Partial Least Squares Structural Equation Modelling (PLS-SEM) technique was used to test the research hypotheses (SmartPLS-GmbH, 2020). PLSSEM is used widely in the field of management to analyze the cause and effect relationships between latent variables. The PLS-SEM has been used because of its suitability for small samples, predicting complex models, and exploratory type of research (Kumar, et al., 2020). Smart-PLS 3.0 software is mainly used for the data analysis in this study.

\section{Analysis and Results}

\subsection{Demographic Profile of Respondents}

Out of the 275 participants, $50.2 \%$ were male and $49.8 \%$ were female. A majority of the respondents $(49.1 \%)$ belong to the $25-30$ age category and $34.9 \%$ of the respondents belong to the 18 25 age category. $13.1 \%$ and $2.9 \%$ of the respondents belong to the $30-40$ and more than 40 age categories respectively. A great majority of the participants (56\%) are employed for wages and $33.8 \%$ of the participants are undergraduates.8.7\% of them are self-employed and the remaining ones are unemployed. Out of the 275 respondents, 206 respondents use the COD payment method as their main payment option in online shopping.

\subsection{Reliability and Validity Analysis}

Using Smart-PLS 3.0 software, the following path model was created including all identified latent variables (see Figure 3). 
The convergent validity is assessed through Cronbach's alpha, composite reliability (CR), and average variance extracted (AVE) (Kumar, et al., 2020). All the values are in the acceptable range as shown in below Table 1 and established convergent validity. Composite reliability indicators were higher than 0.7, and internal consistency was assessed via Cronbach's Alpha Coefficient, and all values were above 0.8 , indicating excellent (1.0-0.90) reliability for all the constructs. The average of variance extracted (AVE) was also examined for each construct, and values were substantially higher than the suggested 0.5 thresholds (Kumar, et al., 2020). Variance Inflation Factor (VIF) is usually considered to identify the amount of multicollinearity among the set of multiple regression variables. As the resultant VIF values for all variables were equal to 1.00, it indicated that no high multicollinearity between the above variables.

Figure 3. Path Model

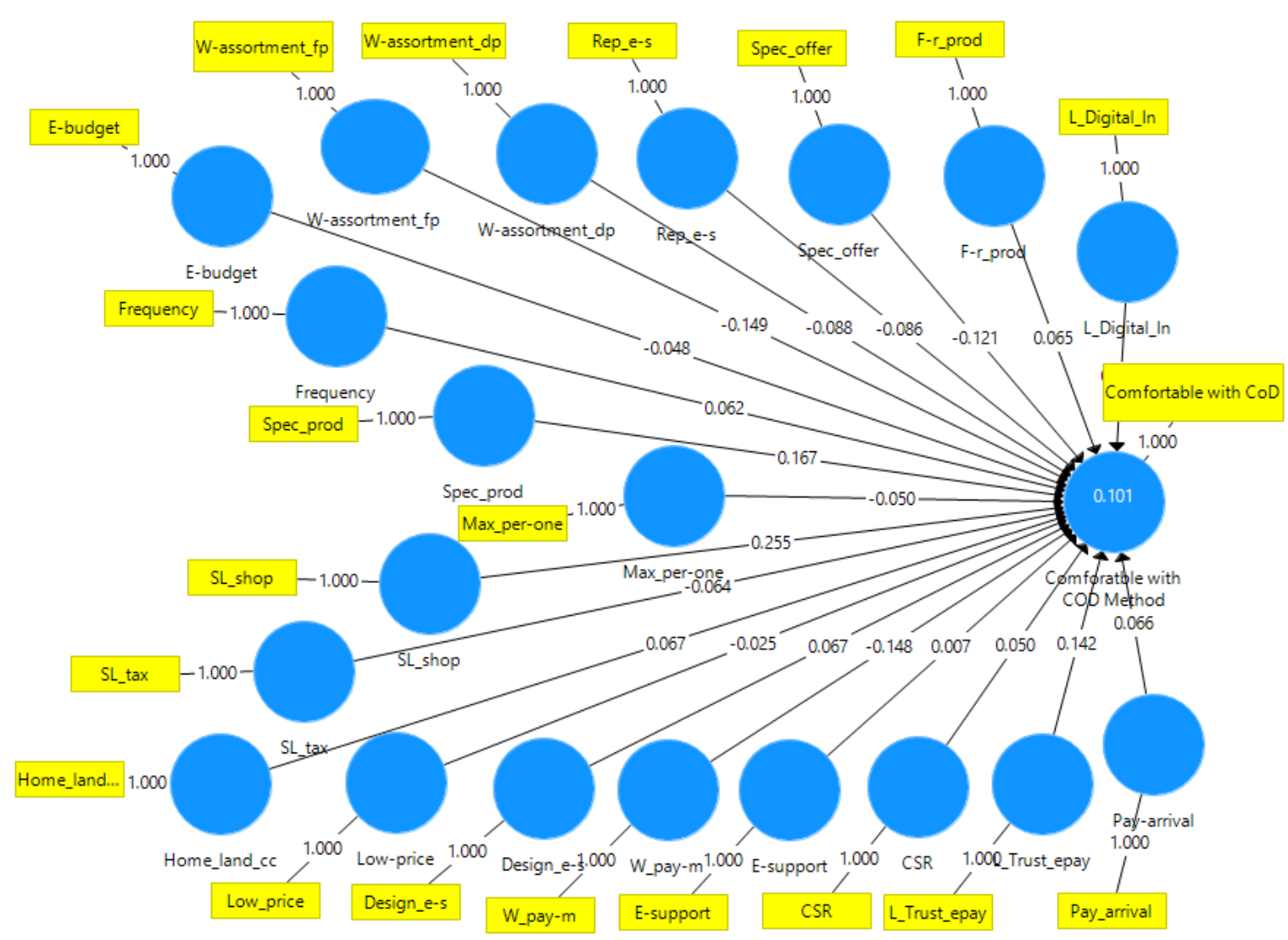

Table 1. Convergent Validity

\begin{tabular}{cccc}
\hline & Cronbach's Alpha & $\begin{array}{c}\text { Composite } \\
\text { Reliability }\end{array}$ & $\begin{array}{c}\text { Average Variance } \\
\text { Extracted (AVE) }\end{array}$ \\
\hline CSR & 1 & 1 & 1 \\
\hline Comfortable with COD Method & 1 & 1 & 1 \\
\hline Design_e-s & 1 & 1 & 1 \\
\hline E-budget & 1 & 1 & 1 \\
\hline E-support & 1 & 1 & 1 \\
\hline F-r_prod & 1 & 1 & 1 \\
\hline Frequency & 1 & 1 & 1 \\
\hline Home_land_cc & 1 & 1 & 1 \\
\hline L_Digital_In & 1 & 1 & \\
\hline L_Trust_epay & 1 & 1 & \\
\hline
\end{tabular}




\begin{tabular}{clll}
\hline Low-price & 1 & 1 & 1 \\
\hline Max_per-one & 1 & 1 & 1 \\
\hline Pay-arrival_ & 1 & 1 & 1 \\
\hline Rep_e-s & 1 & 1 & 1 \\
\hline SL_shop & 1 & 1 & 1 \\
\hline SL_tax & 1 & 1 & 1 \\
\hline Spec_offer & 1 & 1 & 1 \\
\hline Spec_prod & 1 & 1 & 1 \\
\hline W-assortment_dp & 1 & 1 & 1 \\
\hline W-assortment_fp & 1 & 1 & 1 \\
\hline W_pay-m & 1 & 1 & 1
\end{tabular}

The discriminant validity is tested through heterotrait-monotrait ratio (HTMT). The literature suggests HTMT value must be below 0.90 (Kumar, et al., 2020). Table 2 presents the results and confirms discriminant validity.

Table 2. Discriminant Validity

\begin{tabular}{|c|c|c|c|c|c|c|c|c|c|c|}
\hline & CSR & $\begin{array}{c}\text { Comforatble } \\
\text { with COD } \\
\text { Method } \\
\end{array}$ & $\begin{array}{c}\text { Design_e- } \\
\mathrm{s} \\
\end{array}$ & $\begin{array}{c}\text { E- } \\
\text { budget }\end{array}$ & $\begin{array}{c}\text { E- } \\
\text { support }\end{array}$ & F-r_prod & Frequency & Home_land_cc & L_Digital_In & L_trust_epay \\
\hline CSR & 1 & & & & & & & & & \\
\hline \multirow{2}{*}{\multicolumn{11}{|c|}{$\begin{array}{l}\text { Comforatble } \\
\text { with COD }\end{array}$}} \\
\hline & & & & & & & & & & \\
\hline Method & 0.033 & 1 & & & & & & & & \\
\hline Design_e-s & 0.238 & 0.09 & 1 & & & & & & & \\
\hline E-budget & 0.23 & 0.03 & 0.328 & 1 & & & & & & \\
\hline E-support & 0.243 & 0.065 & 0.418 & 0.368 & 1 & & & & & \\
\hline F-r_prod & 0.361 & 0.099 & 0.356 & 0.277 & 0.526 & 1 & & & & \\
\hline Frequency & 0.219 & 0.115 & 0.437 & 0.478 & 0.34 & 0.362 & 1 & & & \\
\hline Home_land_cc & 0.256 & 0.067 & 0.42 & 0.242 & 0.354 & 0.288 & 0.322 & 1 & & \\
\hline L_Digital_In & 0.239 & 0.111 & 0.173 & 0.233 & 0.27 & 0.319 & 0.315 & 0.197 & 1 & \\
\hline L_Trust_epay & 0.302 & 0.114 & 0.2 & 0.255 & 0.418 & 0.365 & 0.341 & 0.192 & 0.463 & 1 \\
\hline Low-price & 0.186 & -0.007 & 0.531 & 0.266 & 0.488 & 0.361 & 0.295 & 0.339 & 0.184 & 0.197 \\
\hline Max_per-one & 0.065 & 0 & 0.381 & 0.447 & 0.302 & 0.228 & 0.414 & 0.232 & 0.2 & 0.156 \\
\hline Pay-arrival__ & -0.172 & 0.076 & 0.099 & 0.095 & 0.105 & 0.005 & 0.072 & 0.073 & 0.025 & 0.05 \\
\hline Rep_e-s & 0.066 & 0.025 & 0.357 & 0.213 & 0.48 & 0.34 & 0.209 & 0.294 & 0.257 & 0.265 \\
\hline SL_shop & 0.126 & 0.167 & 0.416 & 0.418 & 0.574 & 0.368 & 0.388 & 0.448 & 0.323 & 0.245 \\
\hline SL_tax & 0.269 & -0.012 & 0.19 & 0.257 & 0.31 & 0.248 & 0.215 & 0.436 & 0.135 & 0.163 \\
\hline Spec_offer & 0.26 & -0.011 & 0.48 & 0.315 & 0.472 & 0.382 & 0.309 & 0.389 & 0.187 & 0.355 \\
\hline Spec_prod & 0.179 & 0.079 & 0.418 & 0.284 & 0.395 & 0.349 & 0.344 & 0.448 & 0.244 & 0.255 \\
\hline W-assortment_dp & 0.255 & 0.048 & 0.454 & 0.37 & 0.391 & 0.34 & 0.413 & 0.519 & 0.245 & 0.321 \\
\hline W-assortment_fp & 0.246 & -0.025 & 0.385 & 0.315 & 0.43 & 0.326 & 0.314 & 0.437 & 0.102 & 0.242 \\
\hline W_pay-m & 0.348 & 0.008 & 0.24 & 0.251 & 0.537 & 0.372 & 0.284 & 0.414 & 0.305 & 0.418 \\
\hline
\end{tabular}

Table 2. Discriminant Validity (Part 2) 


\begin{tabular}{|c|c|c|c|c|c|c|c|c|c|c|c|}
\hline & Low-price & $\begin{array}{c}\text { Max_per- } \\
\text { one }\end{array}$ & $\begin{array}{c}\text { Pay- } \\
\text { arrival_ }\end{array}$ & $\begin{array}{c}\text { Rep_e- } \\
\text { s }\end{array}$ & $\begin{array}{l}\mathrm{SL}_{-} \\
\text {shop }\end{array}$ & SL_tax & Spec_offer & Spec_prod & $\begin{array}{l}\text { W-assort } \\
\text { ment_dp }\end{array}$ & $\begin{array}{l}\text { W-assort } \\
\text { ment_fp }\end{array}$ & $\begin{array}{c}\text { W_pay- } \\
\text { m }\end{array}$ \\
\hline \multicolumn{12}{|l|}{ CSR } \\
\hline \multicolumn{3}{|l|}{ with COD } & & & & & & & & & \\
\hline \multicolumn{12}{|l|}{ Method } \\
\hline \multicolumn{12}{|l|}{ Design_e-s } \\
\hline \multicolumn{12}{|l|}{ E-budget } \\
\hline \multicolumn{12}{|l|}{ E-support } \\
\hline \multicolumn{12}{|l|}{ F-r_prod } \\
\hline \multicolumn{12}{|l|}{ Frequency } \\
\hline \multicolumn{12}{|l|}{ Home_land_cc } \\
\hline \multicolumn{12}{|l|}{ L_Digital_In } \\
\hline \multicolumn{12}{|l|}{ L_Trust_epay } \\
\hline Low-price & 1 & & & & & & & & & & \\
\hline Max_per-one & 0.376 & 1 & & & & & & & & & \\
\hline Pay-arrival_ & 0.016 & 0.017 & 1 & & & & & & & & \\
\hline Rep_e-s & 0.385 & 0.286 & 0.109 & 1 & & & & & & & \\
\hline SL_shop & 0.343 & 0.325 & 0.125 & 0.444 & 1 & & & & & & \\
\hline $\mathrm{SL} \_$tax & 0.188 & 0.179 & -0.038 & 0.156 & 0.33 & 1 & & & & & \\
\hline Spec_offer & 0.66 & 0.354 & 0.084 & 0.333 & 0.337 & 0.221 & 1 & & & & \\
\hline Spec_prod & 0.588 & 0.42 & 0.099 & 0.375 & 0.345 & 0.274 & 0.518 & 1 & & & \\
\hline $\mathrm{W}$-assortment_dp & 0.424 & 0.285 & 0.126 & 0.324 & 0.499 & 0.241 & 0.478 & 0.548 & 1 & & \\
\hline W-assortment_fp & 0.467 & 0.278 & 0.054 & 0.266 & 0.395 & 0.259 & 0.446 & 0.561 & 0.631 & 1 & \\
\hline W_pay-m & 0.319 & 0.252 & 0.079 & 0.295 & 0.391 & 0.409 & 0.252 & 0.274 & 0.191 & 0.208 & 1 \\
\hline
\end{tabular}

\subsection{Confirmatory Factor Analysis}

This study conducted a confirmatory factor analysis to assess the measurement model's overall fit. The model is initially evaluated based on the coefficient of determination R2 and the significance level as suggested in PLS analysis. The output variable COD has R2 value of 0.1 , which indicated $10 \%$ of the explaining power of the model as shown above (see Figure 3). Although R2 of 0.1 is considered weak, it quite good as this is a novel research area in the Sri Lankan context. However, in the SEM analysis, different indicators such as Standardized Root Mean Square Residual (SRMR) and Normed Fit Index (NFI) are considered to assess the quality of the model (SmartPLS-GmbH, 2020). Before testing the structural model, fit adjustment with SRMR value was evaluated. The SRMR is defined as the difference between the observed correlation and the model implied correlation matrix. Thus, it allows assessing the average magnitude of the discrepancies between observed and expected correlations as an absolute measure of (model) fit criterion. A value of less than 0.10 or 0.08 is considered a good fit (SmartPLS-GmbH, 2020). The result was 0.00, which indicated a good fit adjustment. And The NFI represents an incremental fit measure and NFI values above 0.9 usually represent an acceptable fit (SmartPLS-GmbH, 2020). The result was 1.0 which indicated a good fit adjustment.

\section{4..4 Structural Model and Hypothesis Tests}

The structural model was tested by examining the path coefficients and their significance levels in PLS. The PLS bootstrapping approach was used for this purpose (see Figure 4). The t-statistics were considered for all the variables. The results obtained from PLS bootstrapping are shown in Table 3 
(data were sorted based on the P-Values). There are a total of 20 hypotheses proposed in this study. Table 5 indicates that hypotheses SL_shop (P - 0.008) is supported at a significance level of 0.05 and Spec_prod ( $P$ - 0.093) is significant at a significant level of 0.10 . Considering the $P$ values (closer to 0.1 significant level), W_pay-m (P - 0.113), W-assortment_fp (P - 0.115) and L_Trust_epay(P-0.147) were also identified as the subsequent significant hypotheses.

Figure 4. Bootstrapping Results

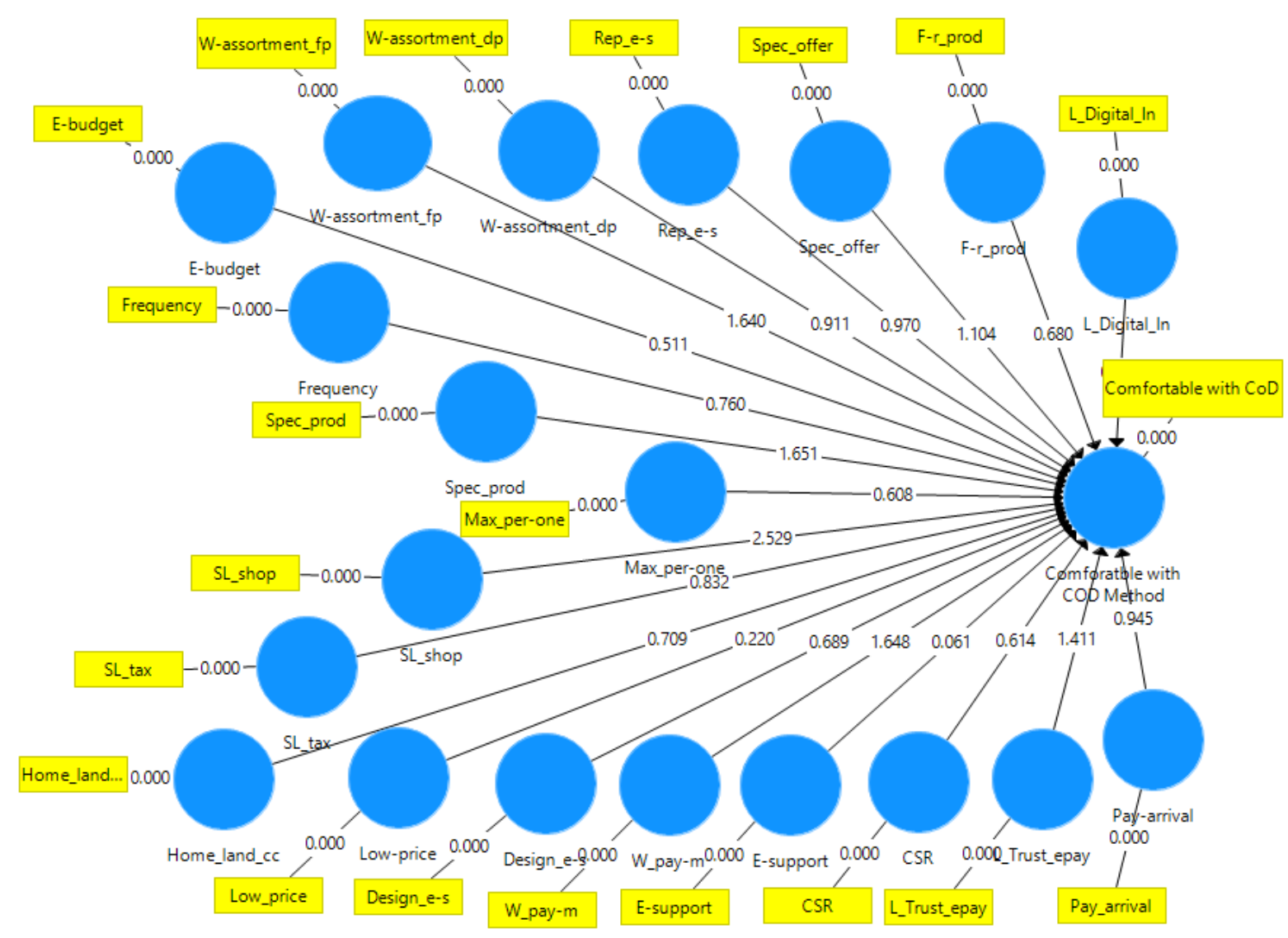

Table 3. Path Coefficient and Hypothesis Results

\begin{tabular}{ccccc}
\hline & $\begin{array}{c}\text { Path } \\
\text { Coefficient }\end{array}$ & $\begin{array}{c}\text { Standard Deviation } \\
\text { (STDEV) }\end{array}$ & $\begin{array}{c}\text { T Statistics } \\
\text { (|O/STDEV I) }\end{array}$ & $\begin{array}{c}\text { P } \\
\text { Values }\end{array}$ \\
\hline $\begin{array}{c}\text { SL_shop -> Comforatble with COD } \\
\text { Method }\end{array}$ & 0.255 & 0.096 & 2.652 & 0.008 \\
\hline $\begin{array}{c}\text { Spec_prod -> Comforatble with COD } \\
\text { Method }\end{array}$ & 0.167 & 0.1 & 1.681 & 0.093 \\
\hline $\begin{array}{c}\text { W_pay-m -> Comforatble with COD } \\
\text { Method }\end{array}$ & -0.148 & 0.093 & 1.586 & 0.113 \\
\hline $\begin{array}{c}\text { W-assortment_fp - Comforatble with } \\
\text { COD Method }\end{array}$ & -0.149 & 0.095 & 1.577 & 0.115 \\
\hline $\begin{array}{c}\text { L_Trust_epay -> Comforatble with } \\
\text { COD Method }\end{array}$ & 0.142 & 0.098 & 1.451 & 0.147 \\
\hline $\begin{array}{c}\text { Spec_offer -> Comforatble with COD } \\
\text { Method }\end{array}$ & -0.121 & 0.106 & 1.141 & 0.254 \\
\hline $\begin{array}{c}\text { Rep_e-s -> Comforatble with COD } \\
\text { Method }\end{array}$ & -0.086 & 0.084 & 1.029 & 0.304 \\
\hline $\begin{array}{c}\text { Pay-arrival_-> Comfortable with } \\
\text { COD Method }\end{array}$ & 0.066 & 0.07 & 0.945 & 0.345 \\
\hline
\end{tabular}




\begin{tabular}{|c|c|c|c|c|}
\hline $\begin{array}{r}\text { W-assortment_dp }->\text { Comfo } \\
\text { COD Method }\end{array}$ & -0.088 & 0.098 & 0.899 & 0.369 \\
\hline \multicolumn{5}{|c|}{ SL_tax $->$ Comforatble with COD } \\
\hline Method & -0.064 & 0.08 & 0.805 & 0.421 \\
\hline \multicolumn{5}{|c|}{ Frequency $->$ Comforatble with COD } \\
\hline Method & 0.062 & 0.08 & 0.772 & 0.44 \\
\hline \multicolumn{5}{|c|}{ Design_e-s -> Comforatble with COD } \\
\hline Method & 0.067 & 0.091 & 0.737 & 0.461 \\
\hline \multicolumn{5}{|c|}{ F-r_prod -> Comforatble with COD } \\
\hline Method & 0.065 & 0.089 & 0.723 & 0.47 \\
\hline \multicolumn{5}{|c|}{ Home_land_cc -> Comforatble with } \\
\hline COD Method & 0.067 & 0.098 & 0.681 & 0.496 \\
\hline \multicolumn{5}{|c|}{ CSR -> Comforatble with COD } \\
\hline Method & 0.05 & 0.081 & 0.626 & 0.531 \\
\hline \multicolumn{5}{|c|}{ Max_per-one -> Comforatble with } \\
\hline COD Method & -0.05 & 0.085 & 0.585 & 0.559 \\
\hline \multicolumn{5}{|c|}{ E-budget -> Comforatble with COD } \\
\hline Method & -0.048 & 0.095 & 0.51 & 0.61 \\
\hline \multicolumn{5}{|c|}{ Low-price -> Comforatble with COD } \\
\hline Method & -0.025 & 0.113 & 0.218 & 0.828 \\
\hline \multicolumn{5}{|c|}{ E-support -> Comforatble with COD } \\
\hline Method & 0.007 & 0.107 & 0.068 & 0.945 \\
\hline \multicolumn{5}{|c|}{ L_Digital_In $->$ Comforatble with } \\
\hline COD Method & 0.003 & 0.084 & 0.032 & 0.974 \\
\hline
\end{tabular}

\section{Discussion and Managerial Implications}

Consequently, it can be revealed that the factor - 'The Sri Lankan origin of the online seller' [SL_shop] has significantly influenced the preference of the COD payment method while shopping online. Similarly, a study was done by Pencarelli, Skerhakova, Taha, \& Valentiny (2018) discovered that the Italian origin of the online seller (as a factor of e-shop preference) increases the preference of the COD method. "This may be because COD can only be used when e-shop is established in Italy; in the case of foreign e-shops, it is not possible to use COD as a payment method, which (logically) increases the use of prepaid cards and PayPal" (Pencarelli, et al., 2018). Correspondingly, Polasik \& Fiszeder (2010) also stated that COD is a method that can be applied on the domestic market solely and practically cannot be used to service foreign transactions due to that posts offices and courier delivery companies are not interested in servicing trans-border payments. Hence, these statements can be further confirmed with the results obtained from the Sri Lankan context as well. 'Availability of wide choice of payment methods [W_pay-m]' was also an important factor which can be confirmed with the results of the above studies ( Pencarelli, et al., 2018; Polasik \& Fiszeder, 2010)). The factor' Lack of trust on online payments [L_Trust_epay]' can be accepted as a significant factor that influences Sri Lankan customers' preference of the COD method and this result is aligned with the many studies conducted in the developing countries ( Puneet Bhalla, 2019); Dudharejia, 2018); Jana, 2017), (courier.lk, 2020), etc)). The factor 'Selling specialized products by the online seller [Spec_prod]' has significantly influenced the preference of the COD and this may be because some startup companies have been increasingly using the social media platforms to promote their specialized products and they allow customers to directly place orders via those platforms facilitating the COD service as the payment option. The factor 'Offering a wide assortment of foreign products by the online seller [Wassortment_fp]' also considerably influenced the preference of the COD payment method while shopping online. Aligning with that, it can be further suggested that, a tendency of purchasing foreign products can be seen among the Sri Lankan Online customers when they are allowed to make their payments using the COD payment option.

As a result of the above analysis, 'The Sri Lankan origin of the online seller [SL_shop]', Selling specialized products by the online seller [Spec_prod], 'Availability of wide choice of payment methods 
[W_pay-m]', 'Offering a wide assortment of foreign products by the online seller [W-assortment_fp]', 'Lack of trust on online payments [L_Trust_epay]' can be indicated as the critical factors influencing online customers' preference of cash on delivery method in the Sri Lankan context. Once reviewing the comments given by the respondents who do not use the COD as the payment option in online shopping, Easiness of doing online transactions, Not availability of the given address at the times of goods arrived, Not interested in online shopping and Lacking knowledge on COD method can be identified as the main reasons for avoiding the COD payment option. The majority of them stated that their preferred payment option is the usage of Debit/credit cards and subsequently the internet banking method can be indicated as the next popular method. Among the above-identified critical factors, lack of trust in online payments can be identified as the main obstacle for the development of the E-commerce industry. Although the Sri Lankan economy is still mostly based on cash transactions, currently a growing trend of using debit/credit cards and internet banking services can be seen among young adults. Hence, the results of this study further reveal the importance of revitalizing the developments of sophisticated infrastructures that facilitate the future needs of secure and reliable digital transactions as well as the importance of educating and convincing the people on the benefits of e-transactions. As a consequence, the adverse effects of COD payment options experienced by the e-retailers and delivery service providers can be mitigated shortly. As far as practical implications are concerned, this study can help E-retailers in Sri Lanka to make decisions about the usage of appropriate payment methods for E-commerce transactions. Allowing customers to make their transactions in the way that they prefer and in the way which is more effective and convenient will enhance the opportunities of expanding the customer base of the E-commerce industry while uplifting its strategic role in the developing nations.

\section{Conclusion}

Just as payment instruments influence the expansion of online shopping, E-commerce is a vital stimulus to the development of payment services. As a developing economy, Sri Lanka tends to have customers with a strong cash preference, and payments have always been one of the main obstacles to shopping online in Sri Lanka. Therefore, the Cash on Delivery method has been playing a significant role in driving the growth of the Sri Lankan E-commerce sector. Although COD is so important, many companies still waver with its processes as the COD service has become a notoriously problematic area when it comes to on-time and successful deliveries. Therefore, this empirical study was conducted to investigate the critical factors influencing the Sri Lankan online customers' preference of COD method to give insights into the management of E-commerce businesses and logistics service providers on the usage of appropriate payment methods for their E-commerce transactions. As a result of survey data analysis, 'The Sri Lankan origin of the online seller [SL_shop]', Selling specialized products by the online seller [Spec_prod], 'Availability of wide choice of payment methods [W_pay-m]', 'Offering a wide assortment of foreign products by the online seller [Wassortment_fp]', 'Lack of trust on online payments [L_Trust_epay]' can be indicated as the critical factors influencing Sri Lankan online customers' preference of cash on delivery method.

The outcome of this study may contribute to the improvements of Sri Lankan E-commerce industry as it highlights the importance of making appropriate decisions on providing diverse payment options for the wide range of online shoppers with different requirements. The present study has certain limitations that need to be acknowledged. The main limit is considered to be the size of the survey sample and the inability to reach all online consumers who prefer to use the COD payment option. Since the study has examined factors influencing the online shopping behavior of consumers in Sri Lanka, the conclusion cannot be generalized for all online consumers. Regarding potential implications for future research, it can be recommended to conduct interviews with the key stakeholders of the Sri Lankan E-commerce sector and the relevant logistics service providers to explore the innovative and reliable payment strategies to enhance the online customers' satisfaction while leading the E-commerce industry to the next level of excellence.

Funding: This research received no external funding. 
Conflicts of Interest: The author declares no conflict of interest. The funders had no role in the design of the study; in the collection, analyses, or interpretation of data; in the writing of the manuscript, or in the decision to publish the results.

\section{References}

Ambekar, A. (2011). The 'Cash on Delivery' Payment Option.

Arora, P., Srivastava, S., \& Majumder, S. (2017). Using Automation Technology and IoT Based Data Capturing to Ensure High-Quality Last Mile Logistics. Proceedings of the 3rd World Conference on Supply Chain Management, 49-56.

Bhalla, P. (2019, May 02). Cash on Delivery (CoD) Pros and Cons in eCommerce. Retrieved from Shiprocket: https://www.shiprocket.in/blog/cash-on-delivery-pros-cons-ecommerce/

Courier.lk. (2020). Cash on Delivery in Sri Lanka: Faster Payments Reliable Service. Retrieved from courier.lk: https://courier.lk/resources/cash-on-delivery-in-sri-lanka-faster-payments-reliable-service

Courier.lk. (2020). courier.lk. Retrieved from Cash-On-Delivery-courier-service-for-ecommerce-businesses: https://courier.lk/resources/cash-on-delivery-courier-service-for-ecommerce-businesses

DeliveryMalli. (2017). Delivery services for ecommerce. Retrieved from Deliverymalli: http://www.deliverymalli.lk/delivery\%20services\%20for\%20ecommerce.html

Dias, M., \& Ranwala, L. (2015). Determinants of Consumer Satisfaction on E-Procurement/ Online Purchasing in Sri Lanka. Proceedings of 8th International Research Conference, KDU. 119-125.

Dudharejia, M. (2018). Cash on Delivery Dominates Indian Ecommerce. Retrieved from Practical E-commerce: https://www.practicalecommerce.com/cash-delivery-dominates-indian-ecommerce

ETNowDigital. (2019). One-third of cash on delivery orders from e-commerce websites not delivered. Retrieved from ETNowNew.com: https://www.timesnownews.com/business-economy/industry/article/one-third-ofcash-on-delivery-orders-from-e-commerce-websites-not-delivered/513801

Fallouh, F. (2019). The future of cash on delivery in the MENA region. Retrieved from Logistics Middle East: https://www.logisticsmiddleeast.com/business/32247-the-future-of-cash-on-delivery-in-the-mena-region

Fernando, N. (2019, May 23). Internet users reluctant to use e-commerce despite high awareness: survey. Retrieved from Daily Mirror: http://www.dailymirror.lk/business-news/Internet-users-reluctant-to-use-e-commercedespite-high-awareness:-survey/273-167697

Howson, A. (2017, March 13). Takas and the difficulties of E-commerce. Retrieved from Roar Media: https://roar.media/english/tech/insights/takas-and-the-difficulties-of-e-commerce/

Jana, S. K. (2017). Measure of E-cash on delivery payment convenience option in the context of demonetization and its effect on customer loyalty. Ushus-Journal of Business Management, 10.

JetEx. (2018). Cash-On-Delivery. Retrieved from jetex: https://www.jetex.lk/service/cash-on-delivery/

Karunarathna, N. (2020). Identifying the ways of delivery performance enhancements in Sri Lankan E commerce Logistics sector with special reference to the Cash on Delivery (COD) method: An Integrative Review. International Journal of Multidisciplinary Sciences and Advanced Technology, 104-119.

Kumar, A., Singh, R. K., \& Modgil, S. (2020). Influence of data-driven supply chain quality management on organizational performance: evidence from retail industry. The TQM Journal, 27.

Kumar, R. (2015, 7). Role of Logistics in eCommerce. Retrieved from iamWire: http://www.iamwire.com/2015/07/role-logistics-e-commerce/119485

LogiNext. (2017). LogiNext. Retrieved from LogiNextSolutions: https://loginextsolutions.com/blog/cash-ondelivery-management/

Pencarelli, T., Skerhakova, V., Taha, V. A., \& Valentiny, T. (2018). Factors determining Italian online shoppers' preference of cash on delivery: Empirical analysis. Polish Journal of Management Studies, 15.

Polasik, M., \& Fiszeder, P. (2010). Factors determining the acceptance of payment methods by online shops in Poland. Electronic Journal, 39.

Puneet Bhalla. (2019,). How does Cash on Delivery (COD) work? Retrieved from Shiprocket: https://www.shiprocket.in/blog/cash-on-delivery-cod-working/

SmartPLS-GmbH. (2020, 11 28). Model Fit. Retrieved from SmartPLS: https://www.smartpls.com/documentation/algorithms-and-techniques/model-fit

Snyder, H. (2019). Literature review as a research methodology: An overview and guidelines. Journal of Business Research, 333-339. 
WorldEconomicForum. (2018). Delivering the Goods: E-commerce Logistics Transformation. Cologny/Geneva, Switzerland: World Economic Forum.

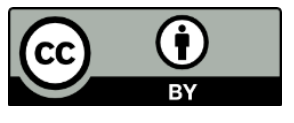

(C) 2020 by the authors. This article is an open-access article distributed under the terms and conditions of the Creative Commons Attribution (CC BY) license (http://creativecommons.org/licenses/by/4.0/). 